TIP Periodica Polytechnica

Transportation Engineering

43(1), pp. 9-14, 2015

DOI: 10.3311/PPtr. 7570

Creative Commons Attribution (i)

RESEARCH ARTICLE

\title{
Status, Trends and Problems of the Road Safety Field in Bulgaria
}

\author{
Daniel VANKOV ${ }^{1 *}$
}

Received 20 June 2014; ACCepted 11 August 2014

\begin{abstract}
The report touches on the road safety performance in the past few years, road user behaviour related problems in the country and the indicative priorities for measures, actions and campaigns that are laid in the National strategy for improvement of the road traffic safety in Bulgaria 2011-2020.
\end{abstract}

\section{Keywords}

Road safety, national strategy, 2011-2020, road safety audit, road user behavior, enforcement measures

\section{Introduction}

Bulgaria is an integral part of the SEE region with several major TEN-T roads going through its territory. At the same time together with Romania and Greece it is one of the worst performing in the EU when speaking about road safety (Vankov et al., 2013). The issue has been in place for decades but just recently faced some improvement. This report uses the latest available 2012 and 2013 statistics to describe the current situation in the country and provides an overview of the road network conditions.

\section{Basic road safety trends}

Despite the gradual decrease of fatalities over the past 5 years (with a stand still in 2013 the number of fatalities is 601 , which happened to be the exact same number of fatalities as in 2012) Bulgaria is still one of the worst performing countries in the EU (European Commission Mobility and Transport Road Safety, 2014).

In those years thanks to the joint efforts of all the actors involved in road safety improvement (government, NGOs, media and private companies), there has been a substantial number of risk prevention campaigns together with wide scale enforcement and improvement in road traffic-related legislation (e.g. increase in the amounts of fines). Bulgaria is also taking active part in the United Nations Decade of Action for Road Safety 2011-2020. The goal of the country is to achieve a $50 \%$ decrease in fatalities and $20 \%$ reduction of serious injuries by 2020 (DOKKPBDP, 2012; DOKKPBDP, 2011) (Fig. 1).

The positive trend for reduction of road traffic victims has remained stable for the years 2008-2012 with no change in fatalities between the years 2012-2013, as it can be seen in Table 1. The difference between 2013 and 2008 is 480 fatalities and 1178 injured less. The number of crashes has dropped by 1097 . If we take the European indicators for economic loss of a person killed (social cost) in car crash it could be said that there have been 1.108 billion euros saved for the society.

${ }^{1}$ Open Youth Institute for Research, Education and Development

6 Kanartche Str. 1756 Sofia, Bulgaria

*Corresponding author, e-mail: info@ired-bg.eu 


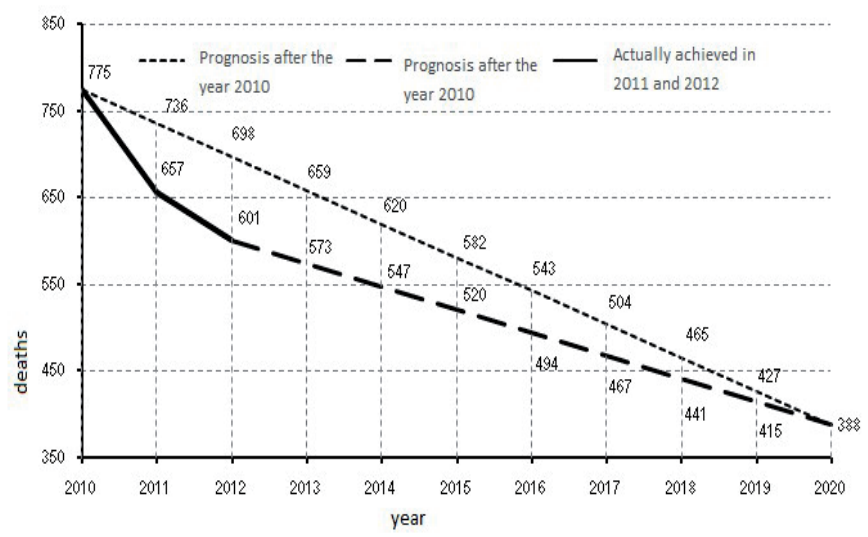

Fig. 1 The foreseen trend towards the achievement of the 2020 goal (Source: State-Public Consultative Commission on the Problems of Road Safety)

Table 1 Data for the period 2008-2013

\begin{tabular}{cccc}
\hline Year & $\begin{array}{c}\text { Number of } \\
\text { crashes }\end{array}$ & People killed & People injured \\
\hline 2013 & 6948 & 601 & 8774 \\
2012 & 6717 & 601 & 8193 \\
2011 & 6640 & 658 & 8303 \\
2010 & 6610 & 776 & 8079 \\
2009 & 7068 & 901 & 8674 \\
2008 & 8045 & 1061 & 9952 \\
\hline
\end{tabular}

Looking at the table above there is a reason for concern however. The low number of crashes and people injured in 2010 is the lowest for the period and since then both values start rising with 2013 seeing the highest numbers. So despite the fact that the number of fatalities is going down, number of people injured is rising which undermines the achievements. A decrease has also been achieved in the indicator "road fatalities per million inhabitants". In 2013 it has been 81.4 people while in 2011 this number was 89.3, in 2010 - 102.9, in $2009-119.1$ and in $2008-141$. Despite the decrease there is still a lot that needs to be done in the country in order to reach the European average of 65 fatalities per one million inhabitants.

The reasons for the big difference in the road safety indicators between the European countries should be sought not only in the different behavior of the road users but also in the safety and age of the cars driven in the country, (Table 2) the condition and quality of road infrastructure, the quality of first aid provided to car crash victims, the novice drivers education and enforcement measures in the country.
Table 2 Cars per age group (2010)

\begin{tabular}{cc}
\hline Vehicle fleet in Bulgaria & European average \\
\hline $8.4 \% \leq 5$ years & $16 \% \leq 2$ years \\
$9.5 \% 5$ to 10 years & $15 \% 2$ to 5 years \\
$24.3 \% 10$ to 15 years & $21 \% 6$ to 10 years \\
$30.5 \% 15$ to 20 years & $33 \%>10$ years \\
$27.3 \%>20$ years & \\
\hline
\end{tabular}

(Source: Ministry of Interior Affairs, ETSC, 2009)

It becomes obvious that a little more than $80 \%$ of the roughly 3.5 million vehicles in Bulgaria are over 10 years old compared to a European average of $48 \%$. And out of all vehicle $90 \%$ are bought used. Yearly between 22,000 and 27,000 new cars are sold in Bulgaria and more than 220,000 used ones (Dabbour, 2012; Peŝiç et al., 2013)

\section{Road network conditions in Bulgaria}

The interurban road network in the country is in overall bad condition with most of the tertiary roads desperately in need of repair with most of the fatalities in the country happening precisely there. The length of the state road network is $19602 \mathrm{~km}$, this includes $541 \mathrm{~km}$ of highways, $2975 \mathrm{~km}$ of primary, $4032 \mathrm{~km}$ of secondary and $12051 \mathrm{~km}$ of tertiary roads. It is obvious from the data above that the secondary and tertiary roads in the country amount at $82.5 \%$ of the total road length and the highways on the other hand are mere $2 \%$. In the flat areas of the country the roads are better maintained and in general the network is denser. Having in mind that Bulgaria is about $40 \%$ mountainous and because of that this area is less populated, it could be concluded that the road network is sufficient. The quality of the roads, according to the "Methodology for measuring and evaluation of the damage of road surface", where the type and quantity of existing damages is measured and evaluated in relationship to the overall surface of the roads, is in:

- good condition with surface damage under $10 \%$ - $34 \%$ of the roads

- average condition with surface damage from $10 \%$ to $30 \%-29 \%$ of the roads

- poor condition with surface damage of more than $30 \%$ $37 \%$ of the roads.

Due to constant lack of funds for maintenance and the delayed in time road repair works the condition of the road network is radically deteriorating. It is estimated that this tendency towards road deterioration has started between 1992 and 1997 and continues up to now. Presently more than $12000 \mathrm{~km}$ or about $60 \%$ of the asphalted state roads are in need of rehabilitation, overhaul or periodical repairs. 


\section{Status of Road Safety Audit (RSA) in Bulgaria}

In Bulgaria road safety audits are carried out obligatory for state roads that are part of the trans-European road network. Road safety audit can also be performed on roads that are not part of the trans-European road network but are using Community funding. Projects, subject to road safety audits are: new construction, reconstruction and overhaul (rehabilitation) of roads. The current number of certified Road Safety Auditors in Bulgaria is 73. The courses are opened to construction engineers and held by the University of Architecture, Civil Engineering and Geodesy. The first group of RS auditors was officially certified in January 2013. Two more courses were held at the end of May 2013. So far only a few road safety audits have been completed in the country.

\section{Key road user behavior problems}

According to the "National strategy for the improvement of traffic safety on the roads of Republic of Bulgaria for the period 2011 - 2020" speeding, drink driving and the use of seat belts and helmets are considered the three main factors for road fatalities. Most of the fatal accidents occur on the secondary road network and out of all the fatalities for $201327 \%$ are passengers, $18 \%$ pedestrians, and $55 \%$ drivers. 287 people have died due to speeding, 18 due to driving under the influence (Open Youth, 2012; Török, 2011; Bosurgi et. al, 2013). In order to address those issues the strategy suggests the implementation of the following actions and measures to strengthen the control of compliance with the rules of traffic:

- Improvement of the strategy and tactics to control the observance of traffic rules according to the results of the accidents and hazardous areas, the establishment of a national system of technical equipment and control systems for the automatic registration of violations of the rules of the road, to adapt and implement best practices for control and enforcement of traffic rules, creating a single database of violations by pedestrians, passengers and other road users.

- Development of technical and better legislative base for the reduction of the incidence of drunk driving and driving under the influence of drugs including the promotion of "drink and drive" services with the help of the public and private sector. Improvement on the control over fatigue, use of safety equipment in vehicles - safety belts, safety helmets and child restraint systems, as well as distracted driving and the use of hands-free devices.

- Encouraging wider cooperation and participation on the side of the media, NGOs and private sector in order to increase the efficiency of the campaigns on compliance with traffic rules.

- Promoting the application of new technologies, providing real-time information about speed limits, equipping vehicles with speed limiters, alcolock devices and others.
- Improving the coordination between licensing authorities, management of unregistered vehicles and vehicles driven by unlicensed drivers, those responsible for the technical condition of the vehicles and equipment and the enforcement of mandatory driver's insurance.

On the other hand the conditions of the interurban road infrastructure, its maintenance and postponed for years rehabilitation plans are further factors contributing to another raising issue in the road user behavior, which is the high levels of driver aggression and road rage.

\section{Priority enforcement measures}

Key enforcement measures to be undertaken in the country include:

Increasing the effectiveness of speed control over the traffic flow with the development of a global plan to build an integrated national system of technical means and systems to control speed modes along the national road network, the municipal network and in the settlements is necessary. It is essential to expand the use of the "sectional" speed control; to improve the organization, tactics and strategy of control over the speed limits using the automatic and manual way of registration of offenses explicit and implicit forms of control for better detection of violations (Török, 2013) and to enhance the green driving (Szendro et al., 2012). It is necessary to improve the legislation regarding the control of the observance of speed limits, shortening the time needed for administrative service and prompt collection of fines; the establishment of organization and arrangements for implementing public-private partnership in the development of systems to control speed limits; to improve the control system over vehicles for public transportation of passengers and cargo (including the condition of the speed limiter, the testimony of digital tachographs, etc.) and the harmonization of legislation in order to support cross-border enforcement.

Reducing the number of drivers operating under the influence of alcohol, drugs or other intoxicating substances. In Bulgaria there is no substantial public rejection of the drivers, driving under the influence of alcohol. The proof is the fact that there is almost no case of serious accident with drunk driver in which the driver has been alone in the car. Therefore, the number of passengers killed or seriously injured in a car accident by a drunk driver, is greater than the number of drivers killed. To limit the number of accidents with fatal outcome involving drivers under the influence of alcohol, the national strategy suggests the following actions to be implemented:

- organization of national campaigns and initiatives to raise public awareness of the dangers associated with driving under the influence of alcohol, and the consequences of such accidents;

- improving the legal framework for fighting the phenomenon in order to increase its effectiveness and application 
on the principle of shared responsibility between those who provide the vehicles, those who are riding in them an those who serve alcohol;

- technical support to activities with regards to driving under the influence in order to improve the detection of this type of crime;

organizing broad public discussions about the need to reduce the legal amount of alcohol in the blood, especially for novice drivers and drivers of public passengers transport and trade goods;

- introduction of alcolock systems in fleet vehicles;

- study and implementation of good practice in other European countries to counteract driving under the influence of alcohol;

- greater reach to the public in the cases of driving or causing of accidents under the influence of alcohol;

- the development of a comprehensive legal framework to fight cases of driving under the influence of drugs;

- the development of a program to supply the control system with the necessary technical means of preventive control and detect the presence of drugs in the blood of drivers.

Increase of the use of safety belts, helmets and child restraints. In 2010, 3071 of the victims, travelling by car and motorcycle (both drivers and passengers), haven't used safety equipment (Beke et al., 2014). Out of those, 239 died. To improve use safety equipment performance the following actions should be taken:

- implementation of large-scale campaigns to raise public awareness and seek the support of non-governmental and private sectors;

- intensified systematic monitoring of the use of safety belts, helmets and child safety systems in the regions and a introduction of measures to improve usability;

- organizing and conducting of open inspections involving community organizations and the media regarding the use of safety equipment by drivers and passengers in the motor vehicles;

- organizing and conducting public discussions on serious injuries that result from non-use of seat belts, helmets and child safety seats;

- incentives to facilitate the purchase of vehicles, fully equipped with safety equipment for the protection from different strokes (e.g. airbags for side impacts), reminder systems and more;

- campaigns with an emphasis on the need to use safety helmets with regards to PTWs and increase of their visibility at night.

\section{Priority communication and training measures}

Measures to be undertaken for the improvement of the system of training of new drivers include the development of a strategy to improve the system of education and training for acquiring driver's license based on European best practices and EU directives. Improvements in the training programs for driver candidates and the introduction of stage/experience based acquisition of driving rights. The call for more objective process of theoretical and practical examination of candidates is recognized and the need of wider set of knowledge (calm driving techniques, ecological and economical driving etc.) The introduction of a system for lifelong learning for drivers as well as an assessment framework for the level of driver training received. The strategy also suggests improvements in the process of education of educators / driver school instructors and the overall ongoing education of all drivers by creating of a legal framework for the continuous driver training. For example introduction of mandatory training for all drivers every few years, stricter training process and examination for offensive drivers and drivers over the age of 65 . In order to reduce the casualties on the road the national strategy is also supporting and encouraging the construction of training polygons for the practice of driving in complex conditions and emergency situations.Priority in communication is given to campaigns aiming to improve the knowledge and responsibility of road users. Formation of coalitions based on public-private partnership to conduct thematic campaigns on traffic safety. Media policy is targeted to reflect the hazards on the road, raising awareness of road users and the responsibility of individual institutions and organizations for road safety. Better dissemination of good practices in media coverage of road safety and activities that clarify the causes of serious accidents with dead and injured people. The development of specialized programs in electronic and print media in series is also to be encouraged.

\section{Road Safety Priorities in Bulgaria}

Driving under the influence, the use of seat belts and child restraint systems, improvement of road infrastructure and carrying out of RSA/I, as well as education and information of road users through public campaigns are the priorities of the road safety field in Bulgaria. Both government and public sector in the country have wholeheartedly accepted the United Nations Decade of Action for Road Safety 2011-2020. Cooperation between the two is further facilitated through the national strategy for the improvement of road safety on the roads of Bulgaria for the period 2011-2020. For the time being the joint efforts are giving results and the country is on track with its goals with steady reduction of fatalities and injuries over 4 consecutive years.

Still a lot of work lies ahead, especially with regards to novice and young drivers (15-24), speeding and drink driving. In 2007 more than $25 \%$ of road accidents are the fault of young 
drivers with under 2 years of experience, gradually this percentage has been brought down to $16 \%$ in 2012 , but the issue still remains since the social cost of road fatalities with youngsters is higher than all other age groups.

Drink driving is major problem in the urban countryside and on the secondary and tertiary roads where most of the incidents with drunk drivers occur, thus stricter enforcement and legislation is needed as well as broader public information campaigning that inform the society about the consequences and effects of drinking and driving.

The use of seatbelts and child restraint system, another high priority in Bulgaria, has also witnessed an increase over the past years. This came as a result of multiple high visibility social campaigns together with an increase of law enforcement and sanctions. With regards to RSA/I as defined in European Directive (2008/96/EU) the legal framework is in place but the first road safety auditors have only recently been certified. For this reason there are still no widely available results from field audits or inspections available in the country.

The need for thorough in-depth crash investigation and analysis has been registered among road safety practitioners, for better understanding and evaluation of the situation.

Despite the decrease in fatalities and injuries as a result of road traffic accidents Bulgaria still remains in the group of countries that perform worse than the EU average. In the first place this is due to a great extent to the condition of road infrastructure in the country. As we have seen more than $50 \%$ of the infrastructure is in need of repair or total overhaul. Secondly, the age and safety of the vehicle fleet is a contributing factor. Even though there has been some renewal in recent years, most of the cars on the country roads are still in the " 10 -year and older" bracket. Nevertheless, the behaviour of road users, the reduction of road rage and aggression are pending issues that need to be tackled. Early education in schools on the topic of road safety and large scale prevention and information campaigning have seen wide spread support by the public.

Thanks to the STA questionnaire that was implemented as part of the ROSEE project, a better picture of data necessities and priorities among decision makers and road safety practitioners, was obtained. Although the responsibility for road safety hasn't been placed under one single authority but spread among different ministries and agencies with respect for their competences, there has been a high level intersector decision making body established under the Prime minister with the capacity to prepare legislative proposals and suggest changes according to the needs of road safety. This Commission also serves as a connection between government and non-government actors, active in the road safety field, and its role is to make communication on the subject easier. Therefore we can conclude that the will for better road safety performance is in place.

\section{Voxpopuli}

Most of the available data reflects the view of the experts and it is believed that they should have the final say about what, how and when should be done. However, science proves by all means that road safety problems are caused mainly by the human factor involved. In order to avoid any bias in the Open Youth Institute for Research, Education and Development (iRED), formerly "Open Youth", we do one more thing. We ask the "human factor" for feedback. In 2011, as part of the European Year of Volunteering flagship project for Bulgaria, "Volunteer! ... through road safety" (VRS), implemented by iRED, three questions were asked to the 915 direct participants immediately after their participation in the VRS activities in order to collect their impression on the efficiency of the tools and informative material, as well as to know their opinion on the measures to take up on the Short Term and on the Long Term.

1. What is the most effective measure to reduce the number of deaths on the roads in the SHORT TERM?

- $32 \%$ : increase the amount of fines

- $17 \%$ : repair the road infrastructure

- $16 \%$ : reduce the corruption among policemen

- $15 \%$ : carry out information and preventive campaigns

- $14 \%$ : submit and enact entirely new laws regarding road safety

- $4 \%$ : nothing can be changed

- $2 \%$ : cannot give answer

The top recommendation, estimated as most valuable by the participants, is to increase the amount of fines, at $32 \%$. The second solution would be to repair road infrastructure followed by keeping on carrying awareness raising campaigns. Just behind, $15 \%$ think of reducing the corruption still existing amongst some policemen and $14 \%$ to create new laws regarding road safety. Those measures are therefore considered by the population as a solution on the short term, but which will need reiteration in order to have an impact on road safety.

2.What is the most effective measure to reduce the number of deaths on the roads in the LONG TERM?

- $21 \%$ submit and enact entirely new laws regarding road safety

- $20 \%$ carry out information and preventive campaigns

- $19 \%$ increase the amount of fines

- $17 \%$ repair the road infrastructure

- $16 \%$ reduce the corruption among policemen

- $4 \%$ cannot give answer

- $3 \%$ nothing can be changed

The most interesting part in the participants' answer on the Long Term is the 2 first answers which complement the first question on the Short Term. Indeed, $20 \%$ answered to carry on 
awareness campaigns and another $21 \%$ claim that new laws should be created for road safety. At the 3 rd place, they maintain by $19 \%$ that the amount of fines should increase.

It is clear that the public opinion should be considered when drafting road safety policy on national level. This way the population will feel responsibility towards achieving the national targets. It is also remarkable to note that only between 3 and $4 \%$ of the population still think that there is nothing to do.

\section{Acknowledgement}

The project titled Road safety in South East European regions - ROSEE presented in this article was approved under the 4th call of the South East Europe Transnational Cooperation Programme and has been commissioned to a consortium of partners from Italy, Romania, Hungary, Greece, Slovenia and Bulgaria. Publication supported by KTI - Institute for Transport Sciences.

\section{References}

Beke, B. M., Sipos, T., Torok, A. (2014) The Mathematical Modelling of the Road Safety Equipment's Market Penetration. American Journal of Vehicle Design. 2 (1). pp. 1-6. DOI: 10.12691/ajvd-2-1-1

Bosurgi, G., D'Andrea, A. and Pellegrino, O. (2013) What variables affect to a greater extent the driver's vision while driving? Transport. (28) 4. pp. 331-340. DOI: $10.3846 / 16484142.2013 .864329$

Dabbour, E. (2012) Using logistic regression to identify risk factors causing rollover collisions. International Journal of Traffic and Transport Engineering. 2 (4) pp. 372-379. DOI: $10.7708 /$ ijtte.2012.2(4).07

DOKKPBD P. (2011) National strategy for the improvement of road safety on the roads of Bulgaria for the period 2011-2020. [Online] Available from: http://dokkpbdp.mvr.bg/AboutUs/documents.htm.[Accessed: $10^{\text {th }}$ May 2014]

DOKKPBD P. (2012) Annual report of the State-Public Consultative Commission on the Problems of Road Safety. [Online] Available from: www.dokkpbdp.mvr.bg. [Accessed: $10^{\text {th }}$ May 2014]
European Commission Mobility and Transport Road Safety.(2014) Statistics - accidents data. [Online] Available from: http://ec.europa.eu/ transport/road_safety/specialist/statistics/index_en.htm.[Accessed: $10^{\text {th }}$ May 2014]

European Commission (2010) Towards a European road safety area: policy orientations on road safety 2011-2020.COM(2010)389 Final. Brussels.

European Commission (2013) Road safety: EU reports lowest ever number of road deaths and takes first step towards an injuries strategy. IP/13/236. Brussels.

ETSC (2014) European Transport Safety Council. [Online] Available from: http://etsc.eu/. [Accessed: $10^{\text {th }}$ May 2014]

Ministry of Transport Information Technology and Communications (2010) Strategy for the development of transport infrastructure of Republic of Bulgaria until 2020. [Online] Available from: http://www.mtitc. government.bg/upload/docs/Transport_Strategy_2020_eng.pdf. [Accessed: 10 ${ }^{\text {th }}$ May 2014]

Open Youth (2012) “Volunteer! ... through road safety.”Final report. [Online] Available from: http://roadsafetyvolunteers.open-youth.org. [Accessed: $10^{\text {th }}$ May 2014]

Pešić, D., Vujanića, M., Lipovaca, K., Antić, B. (2013) New method for benchmarking traffic safety level for the territory. Transport. 28 (1). pp. 69-80. DOI: $10.3846 / 16484142.2013 .781539$

Road Infrastructure Agency (2012) Guidelines for the management of road safety infrastructure. [Online] Available from: http://www.api.bg/ files/5313/6838/2610/API-Nasoki-za-upravlenie-na-bezopasnostta. pdf. [Accessed: 10 ${ }^{\text {th }}$ May 2014]

Szendro, G., Csete, M., Torok, A. (2012) Unbridgeable Gap between transport policy and practice in Hungary. Journal of Environmental Engineering and Landscape Management. 20 (2). pp. 104-109. DOI: $10.3846 / 16486897.2012 .660881$

Török, Á. (2011) Investigation of road environment effects on choice of urban and interurban driving speed. International Journal for Traffic and Transport Engineering. 1 (1). pp. 1-9.

Török, Á. (2013) Simplification of Road Transport Infrastructure Layout for Better Self-Explanation. American Journal Of Vehicle Design. 1 (1). pp. 16-20. DOI: 10.12691/ajvd-1-1-3

Vankov, B., Krastev, K., Vankov, D. (2013) National Report BULGARIA. Road safety in South-East European regions - ROSEE project. WP3: Policy and data analysis. [Online] Available from: http://rosee-project. eu/en/downloads. [Accessed: $10^{\text {th }}$ May 2014] 